\title{
Research on the Training Mode of Innovation Talents for Key National Science \& Technology Specific Projects under the Matching of Supply and Demand
}

\author{
Yingjin Lu \\ School of Management and Economics \\ University of Electronic Science and Technology of China \\ Chengdu, China \\ luyingjin@uestc.edu.cn
}

\author{
Jing Wang \\ School of Management and Economics \\ University of Electronic Science and Technology of China \\ Chengdu, China
}

\author{
Yuqin Deng \\ School of Management and Economics \\ University of Electronic Science and Technology of China \\ Chengdu, China
}

\begin{abstract}
The innovation talent training model for Key National Science \& Technology Specific Projects is studied from the point of view of supply and demand matching in this paper. Based on the analysis of the basic quality characteristics of the national key scientific and technical special talents, it puts forward the mode of national science and technology major special talents training and the ways of training. As a part of the national innovation system, the higher engineering education is not only the main base for knowledge innovation, dissemination and application, but also the cradle of cultivating innovative spirit and innovative talents. Higher engineering education should take the initiative to adapt to the needs of social and economic development, update the concept of education, and actively promote innovation and education, and strive to explore the mode of training innovative talents.
\end{abstract}

Keywords-Key National Science \& Technology Specific Projects the alliance between universities and enterprises, the Doctor-of-engineering, cooperation mechanism Introduction

\section{DESCRIPTION OF PROBLEM}

In recent years, a large number of students in colleges of engineering project practice experience gradually become weak link in the higher engineering education, it has become a bottleneck problem of training high-level engineering talent, due to the reasons like the large-scale enrollment expansion in colleges and universities, the lack of education funds investment, and colleges lack attention of the students' engineering practice. At the same time, with the development of the market economy, enterprises had been turned into independent, self-sustaining principals. Due to the concerns of production safety, students' personal safety, confidentiality, manpower and financial investment, etc. Many companies regard it as a burden of accepting students engineering practice, it further increased the difficulty of the students'

Supported by "Special Project in Humanities and Social Sciences by the Ministry of Education of China (Cultivation of engineering and technological talents) (13JDGC002)" engineering practice. To solve the problems of lacking "engineering" and "innovation" in the higher engineering education, many colleges created new mechanism of cultivating engineering talents with school-enterprise integration, double tutorial system, ordering cultivation and innovation of "industry-university-institute" cooperation. But for various reasons, the cooperation mechanism failed to solve the problems of school-enterprise integration fundamentally. In October 2011, the academic degrees' committee of the state council list 24 colleges and graduate school of Chinese academy of sciences as first pilot units of cultivating engineering talents of science and technology with schoolenterprise integration for major national scientific and technological projects. The major national scientific and technological projects is used for achieving national goals, completing the major strategic products, key generic technology and major projects in a certain time through the core technology breakthrough and resources integration, it is a top priority of the development of science and technology. With the deployment and implementation of major national scientific and technological projects, it will further enhance our country's capacity for independent innovation, speed up cultivating strategic emerging industries, provide technology support to improve the core competitiveness of our country. At the same time, the implementation of major national science and technology projects guides the cultivation of the higher education graduate students. It's both the starting point of cultivating graduate student strategic, and the essences of major national science and technology special personnel training, to cultivate and practice a great number of graduate students who stand in accord with national requirements of frontier science and technology, and understand the latest trends of the discipline. 
In the process of graduate student training in higher education, graduate students are in the stage of use tools, but doctors need to learn to create tools. In the process of creation, the most difficult thing is to find the direction. The implementation of major scientific and technological projects, only if following the new trends of subject development, could make the scientific research topic selection of engineering doctors advanced and innovative. Graduate students directly involved in the national science and technology major projects, allow them aiming at major national strategic demand and international frontier discipline development with no distance, refining science problem, breaking through the key technology, and improving their ability of scientific research core. By participating in major national scientific and technological projects, engineering doctors could get exercise during the declaration of major projects, quarterly summary, intermediate inspection report, etc. And combine with their thesis proposal and complete closely. By this way improving their actual ability to analyze and solve problems, and strengthen their innovation consciousness and scientific diathesis.

At present, there are many researches of innovative talents and teams for major national scientific and technological projects, but the research results of national major projects of science and technology talent demand and higher engineering education personnel training mode aim at supply and demand matching is less. And the independent innovation consciousness and innovation ability of national major projects of science and technology talents is the core target of higher engineering education talent training. This paper constructed the national major projects of science and technology talent cohesion theory model based on the theory of scientific research team needs and organizational support, and analyzed its Structure, function and operating mechanism.

\section{THE BASIC QUALITY ANALYSIS OF MAJOR NATIONAL SCIENTIFIC AND TECHNOLOGICAL PROJECTS ENGINEERING TALENTS}

National major projects of science and technology talents are all kinds of talents with innovative consciousness and innovative ability cultivated through the implementation of major national science and technology projects, including with leading-edge level strategic scientists, senior engineering and technical personnel, academic leaders and young and middleaged high-level experts etc. Innovation consciousness and innovation ability includes not only the discovery of new scientific principles and theoretical breakthrough and development, but also theories applied to transform nature of technological inventions and reform and innovation in major social sector.

\section{A. The structure of knowledge}

Structure of knowledge means a knowledge system with a certain level and mutual synergy, through the selection and combination of knowledge, to achieve one's stated goals. National major projects of science and technology talents must have a deep and wide range of basic theoretical knowledge first. Basic theoretical knowledge includes two aspects, science and the humanities, they are basis of the survival and development, and basis of knowledge extension, professional and quality cultivation. Innovation not only relies on innovative spirit and enthusiasm. It must be based on the abundance of energy. Talent of innovation quality must have fund of knowledge, not only grasp the basic theory, basic knowledge and basic skills of their own subject firmly, but also understand the knowledge of other subjects, and form a comprehensive knowledge structure system, provide the basis and possibility of creative work and their own sustainable development. Besides, the national major projects of science and technology talents need to have a profound professional knowledge. Therefore, for national major projects of science and technology talents in all fields, no matter what works they do, they should have a solid and profound professional knowledge, and master professional skills, especially good at some professional field. For the development frontier of professional field, especially should timely understand and master and apply as soon as possible. Only by this way could stand out from the crowd, and get greater development space.

\section{B. The innovation ability}

Innovation ability is the embodiment of the knowledge application level. The process of knowledge into ability is also the process of achieving the value of knowledge. For national major projects of science and technology talents, innovation ability is divided into the ability of independent thinking and enterprising spirit; With strong comprehensive knowledge, applied research ability and multidimensional thinking of research methods, make mutual infiltration with humanistic spirit and scientific theory, produce and realize the creation; with strong ability to acquire knowledge, master the method and the way to collect knowledge, good at analysis, synthesis and induction the collected knowledge, and have a preliminary ability of knowledge identification and selection; have the ability of communication, organization and coordination. That's the ability of consolidation effect which national major projects of science and technology talents working for interpersonal coordination, communication and cooperation starting from the group interests.

\section{The structure of quality}

Quality refers to the comprehensive of endowments and accomplishment in the physiological and psychological aspects. Quality formed by practicing in the late, on the basis of nature. Refers to the person's personality traits or nonintelligence factors. In general, national major projects of science and technology talents have a good personality psychological quality or non-intelligence factors, have a high "emotional intelligence". They have strong sense of dedication and responsibility, have a persistent pursuit of his career, with the spirit of perseverance, have excellent individual mental quality, strong bear ability, and are able to cope with change and setbacks calmly, handle all kinds of pressure well, and have good ability of coordination and communication. During the innovation practice activity, most of national major projects of science and technology talents have the quality structure of independence, exploratory, tenacity, self-control and collaborative.

Independence refers to the psychological quality that thought and action not easily influenced by other people or the 
outside world, could think, judge, choose and act independently. Someone with strong creativity always have strong self-confidence, hardly follow others or trust authority blindly. Although national major projects of science and technology talents have strong independence, but they are not withdrawn. Exploratory refers to the psychological quality with considerable courage and daring to question, adventurous, bold innovation, and have the courage to take responsibility. Toughness refers to the psychological quality with perseverance, perseverance, and can withstand the numerous failures and setbacks to achieve a goal. Self-control refers to the psychological quality that regulate and control their emotions, constrain their behavior consciously. When they faced with failure, they could adjust their emotions with humor and optimistic attitude, learn lessons from failure. Cooperative refers to the psychological quality that good at understanding communication, understanding partner, good at communication, cooperation, and work together.

\section{Training Mode of NATIONAL SCIENCE AND TeChNOlogy Major Projects of InNOVATIVE TALENTS WITH SUPPLY AND DEMAND MATCHING}

Cultivating talents on national science and technology major projects need to innovate education mode. For a long time, education in our country is always the traditional education mode that the main part is knowledge teaching. If we call this kind of education is accepting education, we can say that innovation education is the education that developed by accepting education, for the purpose of development based on the inheritance, and take the cultivation of national science and technology major special talents as the basic value orientation. Due to the obvious differences in education concept between innovate education and traditional education, therefore, the cultivation of the national major projects of science and technology talents should pay more attention to the following education pattern:

\section{A. The teachers and students interaction, combine with guide and self-study.}

Students study with initiative and creativity mainly reflected in purpose, hard work and creativity of study. Clear learning goals can promote academic progress. We need to make the students fully realize that learning is not only the knowledge, more important is learning to learn, learning is not only for the purpose of the individual, the more important thing is to serve the society. The learning process is a difficult process, you can never get genuine if you fear hardships, you need have the spirit of struggle and insistence. The creation of study requires students to learn creatively, it is not only the essential requirement of cultivating innovative thinking and innovative ability, but also the actual work needs in the future.

\section{B. To take the same weight of inside and outside class education, and combine in school and outside the school}

Inside and outside class are the two basic forms of pilot college education. Inside class education pay attention to the systematic knowledge, it's the main channel for student to learn. Outside class education through extracurricular activities, focuses on the application of the theory and the cultivation of knowledge acquisition ability, it's the strengthening and complement of classroom education. With the implementation of innovative education, adhere to the principle of taking the same weight of inside and outside class education, can not only overcome bad tendency that emphasis on inside class education, ignore outside class education, but also eliminate the one-sided understanding of innovation education is to strengthen the extracurricular education, which good at the cultivation of students' innovation spirit and innovation ability. On the other hand, from the perspective of the functions of university, after entering the middle of the 20th century, with the advent of the era of knowledge economy, higher education has been the center of the society from the edge of the society, colleges are no longer a closed "ivory tower", but an opening, systematic platform for the communication and innovation of knowledge. As the cradle of training innovative talents, the status and roles of college determine its education should be open. Insist the combination of in school and outside the school, not only embodies the openness of education, and the innovation education social atmosphere it built is beneficial to the innovation education from the practice of school education into the internal and external combined with practice.

\section{An equal emphasis on theory and practice, combination between knowledge and application}

National major projects of science and technology talents must have a solid professional theoretical basis. But too much emphasis on the continuity, systematization and integrity of knowledge, emphasis on training students the basic knowledge of charity will make students learning with burden, affect the cultivation of students' innovation ability and spirit. So we must reform the present education model, from the training of the students' curiosity, imagination, intuition and insight, optimize course system and knowledge structure, broaden the knowledge, strengthen practice teaching. Stick to the principle of" An equal emphasis on theory and practice, combination between knowledge and application" design training plan and teaching plan. Take the cultivation of students' innovative spirit and ability to solve practical problems as the basic starting point, elaborate organization theory teaching and practice teaching.

\section{The CUltivation APPROACH FOR NATIONAl MAJOR PROJECTS OF SCIENCE AND TECHNOLOGY TALENTS}

The cultivation of national major projects of science and technology talents is the inevitable requirement of building an innovative country. Colleges must change the old concept of education, fully understand the status of innovation education in quality education, set up the new education idea which take innovation spirit as the value orientation, tread the cultivation of all kinds of talents with innovation spirit and innovation ability as the same important thing that related to national future and national destiny. Establish the consciousness that only innovation education could cultivate innovative talents, only innovative talents could build an innovation-oriented country. Cultivating high quality innovation talents who meet the social need through the implementation of innovative education. 


\section{A. To establish the advanced innovation education culture}

Cultural concept has remarkable influence on talent training. The traditional culture of our country is profound, but some aspects of traditional culture has a negative influence on the innovation education in terms of innovative talent training. Such as the Confucian classics and the doctrine of the mean culture which connect with education closely is particularly emphasized on teaching and learning, and don't allow the suspect, which will lead to people don't want to stir up, afraid to go beyond inevitably. But innovation contains negation, criticism and transcendence. It's the reactionary to innovation that search for obedience and unification. Therefore, to cultivate national major projects of science and technology talents, we must dare to go beyond the traditional culture which hamper innovation education from the value of attitude and cultural emotion. Which means we need to build a loose, active and positive campus cultural environment that beneficial to the national major projects of science and technology talents in colleges.

\section{B. To build a cultivation system for national major projects of science and technology talents with the integration of teaching and scientific research}

To cultivate national major projects of science and technology talents need to build a corresponding training system. At present, our country's higher education can not completely meet the needs of the national major projects of science and technology talents. To build a cultivation system for national major projects of science and technology talents, have to further promote the deep education teaching reform, which means to realize the organic integration of teaching and research, give full play to the university scientific research advantage, make it become the limitless high quality resources and the environment of innovative education.

First, teachers need to attach importance to both teaching and scientific research. The modern university have functions of teaching, innovation and applications of knowledge. Teachers only actively engaged in scientific research could integrate the knowledge obtained from the science and technology innovation activities and innovative knowledge into the curriculum system and teaching, and cultivate students' ability to access to knowledge and the ability to solve the problem with science and technology innovation thinking.

Second, we need to build science and education innovation platform and optimize curriculum system. The cultivation of innovative talents can't just rely on undergraduate, most of the time need to experience bachelor, master, doctor and even postdoctoral education process to complete. But the undergraduate course education is important basis. We need to strengthen general education, the practice ability and independent ability in the undergraduate stage. So we must attach importance to innovation platform construction and knowledge structure optimization, to achieve from the "forcefeeding" teaching to the transformation of "heuristic" teaching, to make the students accept knowledge from passively into actively. At last, the training system of national major projects of science and technology talents should also include the education and edification of humanistic spirit and scientific spirit. The humanistic spirit and scientific spirit is not only the foundation for people's success, is also the soul of colleges. To cultivate national major projects of science and technology talents, must pay attention to cultivate students' correct outlook on life, values and scientific outlook during teaching and research practice. Therefore, should attach great importance to the construction of university cultural innovation, efforts to provide teachers and students a good spiritual home.

\section{To build the institutional environment that conducive to the cultivation of innovative talents}

The cultivation of innovative talents depends on the system innovation. Compared with the developed countries, higher education in our country has the disadvantages of insufficient innovation vitality. To solve the problem fundamentally, we must start from the system construction, change the old education management system and the personnel training mode, actively build system conducive to the growth of innovative talents. Break through the institutional constraints, refresh the university academic organization, in order to realize the organic combination and interaction of teaching and scientific research, making the teaching level higher with a higher scientific research level. To make comprehensive reform in the recruitment and training, improve the selection mechanism and training mode of talents, through institutional guarantee to promote innovative education, promote students' creativity cultivation and personality cultivation

\section{CONCLUSIONS AND SugGestions}

The cultivation of the national major projects of science and technology talents is a comprehensive process, is the systems engineering need to jointly build with the whole society. At the stage of cultivation in college, carry out the heuristic teaching, realize the integration of teaching and research is the key to cultivate national major projects of science and technology talents, and a good system innovation and the cultural environment is an important "Soft environment" that guarantee the healthy growth of talents.

\section{REFERENCES}

[1] Xiaozheng Zhong, Huiqin liu, Yang Jing. Engineering doctoral study [J]. Journal of graduate student education research. 2013.02 (1)

[2] FengXiang Xiao, Xianhui Dong, Weidong Fu, etc. Engineering doctoral degree graduate education present situation and the problems that should be paid attention to $[\mathrm{J}]$. Journal of degree and graduate education, 2014, (3) : 43-47

[3] FengXiang Xiao, Weidong Fu, XiaoQing Lian, etc. Under the cooperative innovation strategy of China's engineering doctoral training mode analysis $[\mathrm{J}]$. Journal of graduate student education research, 2014, (1) : 69-73

[4] ShangKe Zhong. Improve the system of professional engineering doctoral degree education in China and the measures of [J]. Journal of higher engineering education research, 2013, (4) : 160-165

[5] Meirong Zhao, Pan Feng Wu Yue, Shen Yan. Dr Engineering exploration and practice of professional degree graduate training scheme innovation [J]. Journal of tianjin university (social science edition), 2013:81 
[6] Xiuhong Zhao, Zhanyuan Du. It is always in demand for traction to carry out the engineering doctoral $[\mathrm{J}]$. Journal of teaching: higher education BBS, 2015 (10) : 15-15.

[7] Yongwei Zeng, Guorong Liu. Under the background of "excellence initiative" practice teaching system for scientific analysis [J]. Journal of China university teaching, 2011 (7) : 75-78.

[8] Jianzhong Cha. Geared to the needs of the engineering education reform strategy of economic globalization and international cooperation between production $[\mathrm{J}]$. Journal of higher engineering education research, $2008(1): 21-28$. 